\title{
ChemComm
}

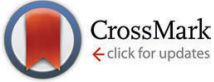

Cite this: Chem. Commun., 2015, 51, 11401

Received 26th May 2015, Accepted 10th June 2015

DOI: $10.1039 / c 5 c c 04326 c$

\section{Copper(I) complexes as alternatives to iridium(III) complexes for highly efficient oxygen sensing $\dagger$}

\author{
Santiago Medina-Rodríguez, ${ }^{a b}$ Francisco J. Orriach-Fernández, ${ }^{b}$ \\ Christopher Poole, ${ }^{\mathrm{C}}$ Prashant Kumar, ${ }^{\mathrm{C}}$ Ángel de la Torre-Vega, ${ }^{* a}$ \\ Jorge F. Fernández-Sánchez, ${ }^{{ }^{b}}$ Etienne Baranoff*c and \\ Alberto Fernández-Gutiérrez ${ }^{\mathrm{b}}$
}

www.rsc.org/chemcomm

The complex $[\mathrm{Cu}(\mathrm{xantphos})(\mathrm{dmp})]\left[\mathrm{PF}_{6}\right]$ (dmp = 2,9-dimethyl-1,10phenanthroline) in a nanostructured metal oxyde matrix shows better sensitivity to oxygen $\left(K_{\mathrm{Sv}}=9.74 \pm 0.87 \mathrm{kPa}^{-1}\right.$ between 0 and $1 \mathrm{kPa} \mathrm{pO}_{2}$ and $5.59 \pm 0.15 \mathrm{kPa}^{-1}$ between 0 and $10 \mathrm{kPa} \mathrm{pO}_{2}$ ) than cyclometallated iridium complexes in the same conditions.

Photoactive complexes based on earth-abundant copper are increasingly studied as alternatives to platinoid metal-based complexes. This is because $\mathrm{Cu}(\mathrm{I})$ complexes have attractive photophysical properties ${ }^{1}$ (e.g. possibly highly emissive metalto-ligand-charge-transfer (MLCT) state, long luminescence lifetimes, large Stokes shift) whilst copper is much more abundant and low-cost than platinoid metals. For example, $\mathrm{Cu}(\mathrm{I})$ complexes have been explored to replace ruthenium(II) complexes as sensitizers for dye-sensitized solar cells (DSSCs) ${ }^{2}$ and platinum(II) and iridium(III) as phosphorescent emitters for organic light-emitting diodes (OLEDs) ${ }^{3}$ and light-emitting electrochemical cells (LEECs). ${ }^{4}$

Optical oxygen sensing is another key technologic area using phosphorescent noble-metal complexes as champion materials. In this case, the emissive triplet state of the dye is quenched by the oxygen, which has a triplet ground state. In practice, the emission intensity of the dye diminishes as the concentration of oxygen increases. The best reported dyes to date (Table 1) are Pt/ PdTFPP (platinum(II)/palladium(II) meso-tetrakis(pentafluorophenyl) porphyrin $)^{5,6}$ and $\mathrm{N969},{ }^{5}$ a cationic cyclometallated iridium complex. Although Pt/PdTFPP are much better performing than iridium complexes, an important advantage of the latter is the possibility to vary the emission colour over the entire visible spectrum. In this context, $\mathrm{Cu}(\mathrm{I})$ complexes are very attractive for

\footnotetext{
${ }^{a}$ Department of Signal Theory, Networking and Communications, CITIC-UGR, University of Granada, C/ Periodista Rafael Gómez 2, E-18071 Granada, Spain.E-mail: atv@ugr.es

${ }^{b}$ Department of Analytical Chemistry, Faculty of Sciences, University of Granada, Avda. Fuentenueva s/n, E-18071 Granada, Spain.E-mail: jffernan@ugr.es

${ }^{c}$ School of Chemistry, University of Birmingham, Edgbaston, B15 2TT, England, UK. E-mail: e.baranoff@bham.ac.uk

$\dagger$ Electronic supplementary information (ESI) available: Additional figures and description of experimental set-up and methods. See DOI: 10.1039/c5cc04326c
}

Table 1 Comparison of the sensitivity of the $\mathrm{O}_{2}$ sensing films under study

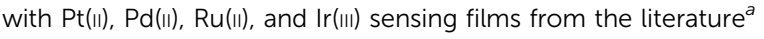

\begin{tabular}{llcll}
\hline \multirow{3}{*}{ Complex } & Support & \multicolumn{2}{c}{ Sensitivity } & \\
\cline { 3 - 4 } PtTFPP & AP200/19 & $K_{\mathrm{SV}}\left(\mathrm{kPa}^{-1}\right)$ & $\Delta \tau_{0.05}(\%)$ & Reference \\
& PS & $25.68^{b}$ & 62.53 & 5 \\
& Silica beads-silicone & $0.4142^{b}$ & - & 5 \\
PdTFPP & Silica beads-silicone & $67.10^{d}$ & - & 6 \\
N969 & AP200/19 & $4.79^{b}$ & - & 6 \\
N1008 & AP200/19 & $1.45^{b}$ & 4.44 & 5 \\
EB146 & AP200/19 & $1.70^{b}$ & 9.43 & 5 \\
ETH -3003 & AP200/19 & $0.711^{b}$ & - & 7 \\
$\mathbf{1}$ & AP200/19 & $5.59^{b}$ & 33.55 & This work \\
& AP200/19 & $9.74^{c}$ & - & This work \\
2 & PS & $0.28^{b}$ & 1.50 & This work \\
2 & AP200/19 & $5.13^{b}$ & - & This work \\
3 & PS & $1.59^{b}$ & - & This work \\
& PS & $2.57^{b}$ & - & This work
\end{tabular}

${ }^{a}$ Structure of complexes from literature are shown in Fig. S1 (ESI). ${ }^{b} \mathrm{pO}_{2}$ between $0-10 \mathrm{kPa} .{ }^{c} p \mathrm{O}_{2}$ between $0-1 \mathrm{kPa} .{ }^{d} p \mathrm{O}_{2}$ between $0-0.1 \mathrm{kPa}$.

sensing of oxygen. However, only few oxygen sensors based on $\mathrm{Cu}(\mathrm{I})$ complexes have been reported to date and all display much lower performance than sensors based on platinoid-group metal complexes. ${ }^{8-14}$

Smith et al. used crystals of $\mathrm{Cu}\left(\mathrm{P}^{\wedge} \mathrm{P}\right)\left(\mathrm{N}^{\wedge} \mathrm{N}\right)^{+}$complexes $\left(\mathrm{P}^{\wedge} \mathrm{P}=\right.$ bis[2-(diphenylphosphino)phenyl]ether (POP) or 4,5-bis(diphenyl phosphino)-9,9-dimethylxanthene (xantphos) and $\mathrm{N}^{\wedge} \mathrm{N}=$ 2,9-dimethyl-1,10-phenanthroline (dmp) or 2,9-diisopropyl-1,10phenanthroline (dipp)) that resulted in very low sensitivity (SternVolmer constant $K_{\mathrm{SV}}$ between 0.002 and $\left.0.058 \mathrm{kPa}^{-1}\right) .{ }^{10,12}$ Wang et al. developed an optical sensing layer based on [Cu(POP)(phencarz)] $\left(\mathrm{BF}_{4}\right)$-PS (PS = polystyrene; phencarz = 2-(9-ethyl-9H-carbaol-2-yl)- $1 H^{-}$ imidazo[4,5-f]-1,10-phenanthroline) showing $K_{\mathrm{SV}}=0.39 \mathrm{kPa}^{-1} \cdot{ }^{11} \mathrm{Shi}$ et al. used MCM-41, a mesoporous material, as solid support for $[\mathrm{Cu}(\mathrm{POP})(\mathrm{PTZ})]\left(\mathrm{BF}_{4}\right)(\mathrm{PTZ}=5$-(2-pyridyl)tetrazole) and achieved the best copper complex-based oxygen sensing film reported so far in the literature with sensitivity to oxygen $K_{\mathrm{SV}}=0.50 \mathrm{kPa}^{-1} \cdot{ }^{9}$

Herein we investigate three $\mathrm{Cu}(\mathrm{I})$ complexes, $[\mathrm{Cu}$ (xantphos) (dmp) $]\left[\mathrm{PF}_{6}\right]$ (1), [Cu(xantphos)(pzpy) $]\left[\mathrm{PF}_{6}\right](2)$, and $\left[\mathrm{Cu}(\text { xantphos })_{2}\right]$ 


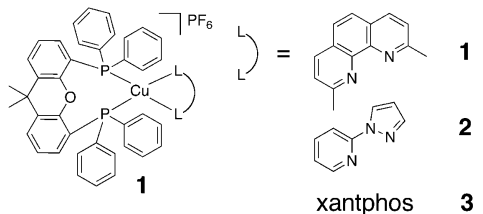

Fig. 1 Chemical structure of the $\mathrm{Cu}(1)$ complexes used in this work.

$\left[\mathrm{PF}_{6}\right](3)\left(\mathrm{dmp}=2,9\right.$-dimethyl-1,10-phenanthroline; pzpy $=2-\left(1 H^{-}\right.$ pyrazol-1-yl)pyridine) (Fig. 1) to develop oxygen-sensitive sensing films with ten times better sensitivity than previously reported copper-based systems. Importantly, we also demonstrate for the first time that these emitters based on earth abundant metals can compete with expensive alternatives such as iridium complexes.

Xantphos is more rigid than POP and so was chosen to limit scrambling of ligands. ${ }^{15}$ The complexes were prepared as described in the literature. ${ }^{16}$ Sensing films were prepared by dissolving the dyes in chloroform and spincoating the solution on AP200/19 nanostructured films or adding polystyrene (PS) and spincoating the solution on glass (see ESI $\dagger$ for details). As such we obtain six different films named X-AP200/19 and X-PS $(X=1,2,3)$.

Compared to other organometallic compounds used in the development of oxygen-sensitive films, the quantum yields of these $\mathrm{Cu}(\mathrm{I}$ )-based films are quite low, $\Phi \approx 0.1$ to 0.3 (Table S1, ESI $\dagger$ ), and future efforts should aim at increasing the brightness of these dyes. When exposed to oxygen, the luminescence of the films is completely quenched (Fig. 2 for $\mathbf{1}$; Fig. S2 and S3, ESI $\dagger$ for 2 and 3) but for 3-AP200/19, in which case the intensity decreased only by half (Fig. S3b, ESI $\dagger$ ). $\ddagger$

The films were characterized first by intensity measurements following the procedure described in ESI. $\uparrow$ The variations of the luminescence intensity with the oxygen concentration as well as the Stern-Volmer plots are shown in Fig. 3 and Fig. S4 (ESI $\dagger$ ) for
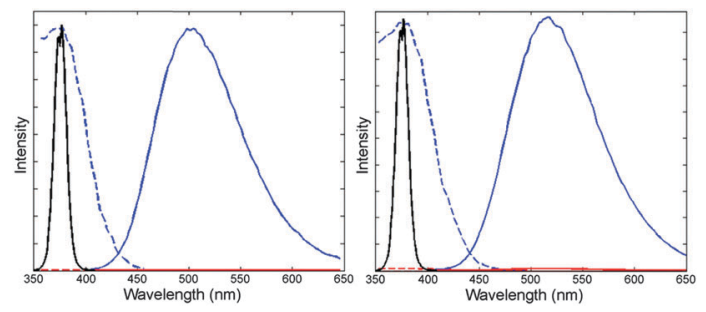

Fig. 2 Excitation (---) and emission (-) spectra of 1-PS (left) and 1-AP200/19 (right) in the presence (red) and absence (blue) of oxygen. The black line is the emission spectrum of the LED $\left(\lambda_{\text {peak }}=375 \mathrm{~nm}\right)$ used
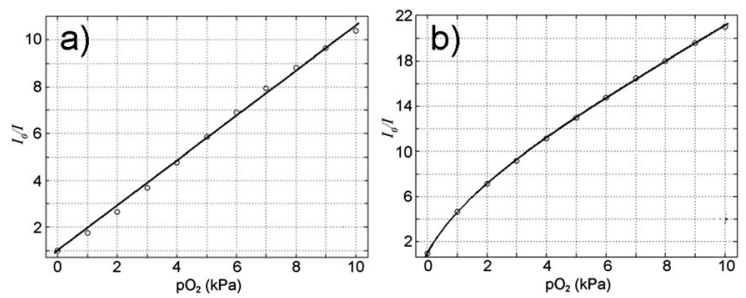

Fig. 3 Stern-Volmer plots in the range $0-10 \mathrm{kPa} \mathrm{O}_{2}$ for (a) 1-PS and (b) 1-AP200/19 obtained by intensity measurements.
Table $2 \mathrm{O}_{2}$ sensitivity of sensing films using luminescence intensity measurements and apparent luminescence lifetimes estimated from phase shift measurements

\begin{tabular}{llll}
\hline Range & Parameters & 1-PS & 1-AP200/19 \\
\hline Intensity measurements ${ }^{a}\left(I_{0} / I\right)$ & & \\
$0-100 \mathrm{kPa} p \mathrm{O}_{2}$ & $K_{\mathrm{SV} 1}\left(\mathrm{kPa}^{-1}\right)$ & $1.628 \pm 0.132^{b}$ & $3.490 \pm 0.107^{b}$ \\
& $x_{1}\left(\mathrm{kPa}^{-1}\right)$ & $0.94 \pm 0.01$ & $0.97 \pm 0.01$ \\
& $K_{\mathrm{SV} 2}$ & $0.00 \pm 0.00$ & $0.0515 \pm 0.0064$ \\
& $x_{2}$ & $0.06 \pm 0.01$ & $0.03 \pm 0.01$ \\
$0-10 \mathrm{kPa} p \mathrm{O}_{2}$ & $R^{2}$ & $0.9623 \pm 0.0075$ & $0.9999 \pm 0.0006$ \\
& $K_{\mathrm{SV} 1}\left(\mathrm{kPa}^{-1}\right)$ & $0.93 \pm 0.07^{c}$ & $5.450 \pm 0.323^{b}$ \\
& $x_{1}$ & $1.0 \pm 0.0$ & $0.9 \pm 0.1$ \\
& $K_{\mathrm{SV} 2}\left(\mathrm{kPa}^{-1}\right)$ & - & $0.200 \pm 0.014$ \\
& $x_{2}$ & - & $0.09 \pm 0.06$ \\
& $R^{2}$ & $0.9926 \pm 0.0115$ & $0.9966 \pm \pm 0.0084$
\end{tabular}

Lifetime measurements ${ }^{a}\left(\tau_{0} / \tau\right)$

$\begin{array}{llll}0-10 \mathrm{kPa} p \mathrm{O}_{2} & K_{\mathrm{SV} 1}\left(\mathrm{kPa}^{-1}\right) & 0.280 \pm 0.040^{b} & 5.590 \pm 0.160^{b} \\ & x_{1} & 0.76 \pm 0.08 & 0.68 \pm 0.09 \\ & K_{\mathrm{SV} 2}\left(\mathrm{kPa}^{-1}\right) & 0.010 \pm 0.020 & 0.030 \pm 0.070 \\ & x_{2} & 0.24 \pm 0.09 & 0.31 \pm 0.08 \\ & R^{2} & 0.9998 \pm 0.0004 & 0.9988 \pm 0.0009 \\ 0-1 \mathrm{kPa} p \mathrm{O}_{2} & K_{\mathrm{SV} 1}\left(\mathrm{kPa}^{-1}\right) & 0.190 \pm 0.010^{b} & 9.740 \pm 0.870^{b} \\ & x_{1} & 0.62 \pm 0.01 & 0.63 \pm 0.09 \\ & K_{\mathrm{SV} 2}\left(\mathrm{kPa}^{-1}\right) & 0.200 \pm 0.030 & 0.090 \pm 0.050 \\ & x_{2} & 0.38 \pm 0.02 & 0.37 \pm 0.08 \\ & R^{2} & 0.9996 \pm 0.0003 & 0.9998 \pm 0.0002\end{array}$

${ }^{a}$ [Dye concentration] $=1.5 \mathrm{mg} \mathrm{mL}^{-1}$; the results are the average of 3 replicas $\pm s t / \sqrt{n}(n=3, t=4.303(2 P=0.05), s=$ standard deviation $)$. ${ }^{b}$ Data fitted with the Demas two-site model. ${ }^{c}$ Data fitted with the Stern-Volmer model.

1-AP200/19 and 1-PS, in Fig. S5 (ESI $\dagger$ ) for 2-AP200/19 and 2-PS and in Fig. S6 (ESI $\dagger$ ) for 3-PS. The fitting parameters for films containing 1 are reported in Table 2 (see Table S2 for other films, ESI $\dagger$ ). As anticipated, the use of the nanostructured support AP200/19 increased the oxygen sensitivity, as shown by the increase of the Stern-Volmer constant values. In particular 1-AP200/19 sensitivity is more than 5 times the sensitivity of 1-PS. Such sensitivity improvement has previously been observed for $\mathrm{Pt}(\mathrm{II}), \mathrm{Ru}(\mathrm{II})$, and $\mathrm{Ir}(\mathrm{III})$ oxygen sensitive dyes ${ }^{5,7,17,18}$ and is now demonstrated for the first time with $\mathrm{Cu}(\mathrm{I})$ dyes, which confirms that the improvement is qualitatively due to the nanostructured film.

The most sensitive sensing films are based on 1- and 2-AP200/19 $\left(K_{\mathrm{SV} 1}=5.45\right.$ and $5.13 \mathrm{kPa}^{-1}$, respectively). Comparing these results with classical $\mathrm{Pt}(\mathrm{II}), \mathrm{Ru}(\mathrm{II})$, and $\mathrm{Ir}(\mathrm{III})$ sensing films using the same nanostructured matrix (see Table 1), it is clear that $\mathrm{Cu}(\mathrm{I})$ sensing films are very promising for $\mathrm{O}_{2}$-sensing applications. Indeed, $\operatorname{Ir}(\mathrm{III})$ sensing films show lower sensitivity. Only PtTFPP shows higher sensitivity in the same condition $\left(K_{\mathrm{SV}}=25.68 \mathrm{kPa}^{-1}\right) .^{5}$

Intensity measurements are not sensitive enough to characterize the sensing films in the range $0-1 \mathrm{kPa} p \mathrm{O}_{2}$. Therefore we used a multifrequency phase-modulation method for luminescence spectroscopy using a rectangular-wave modulated excitation source with a short duty cycle ${ }^{19}$ for measuring lifetime for this range of oxygen concentrations. $\S$ It provides: (1) a more complete characterization of the luminescence system (multiple frequencies measured at once), and (2) an improvement in the accuracy for determining the analyte concentration. ${ }^{19}$

After finding the appropriate modulation frequency for each sensing film for best signal-to-noise ratio, $10 \%$ duty cycle 

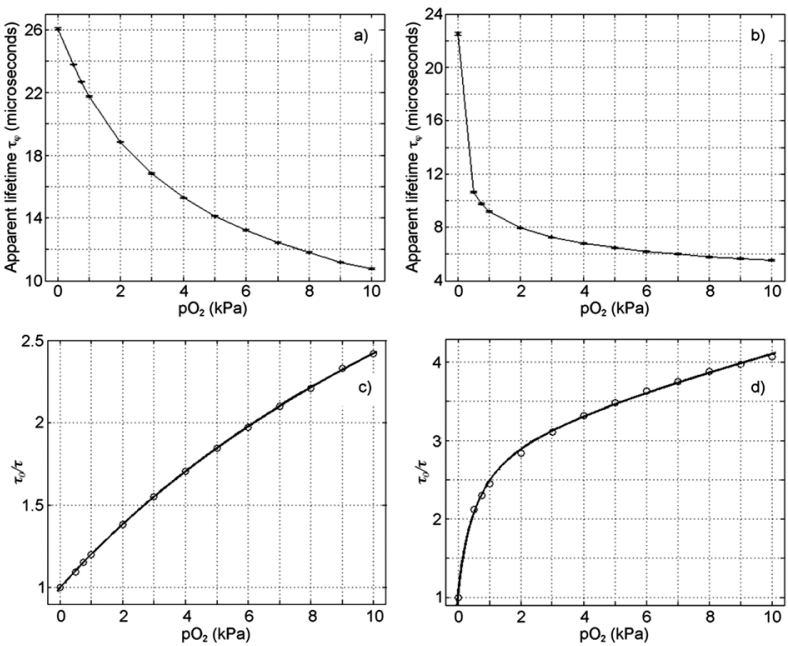

Fig. 4 Apparent lifetimes determined from the phase-shift ( $\tau_{\varphi}$ in $\left.\mu \mathrm{s}\right)$ of (a) 1-PS and (b) 1-AP200/19 at $21{ }^{\circ} \mathrm{C}$ in the range $0-10 \mathrm{kPa} \mathrm{O}$; and Stern-Volmer plot of (c) 1-PS and (d) 1-AP200/19 fitted using the Demas two-site model.

rectangular-wave excitation signals with the selected modulation frequencies (i.e., with fundamental frequencies of $5650 \mathrm{~Hz}$ and $14125 \mathrm{~Hz}$ for 1-PS and 1-AP200/19 films, respectively, see ESI $\dagger$ for details) were used to carry out the calibration of the sensing films. ${ }^{19}$

Oxygen-sensitive properties of 1-PS and 1-AP200/19 were determined following the procedure described in ESI. $\dagger$ The calibration curves for 1-PS and 1-AP200/19 when exposed to different oxygen concentrations are shown in Fig. 4 and the results are summarized in Table 2 . As for intensity measurements, the incorporation of the dye into AP200/19 increased the sensitivity of the film to oxygen. Gratifyingly, intensity and lifetime measurements provided similar results for high oxygen concentrations ( $K_{\mathrm{SV} 1}$ of 1 -AP200/19 by intensity is $5.45 \mathrm{kPa}^{-1}$ and by lifetime is $5.59 \mathrm{kPa}^{-1}$ for the range $0-10 \mathrm{kPa} \mathrm{O}_{2}$ ). At low oxygen concentrations (range $0-1 \mathrm{kPa} \mathrm{O}_{2}$ ) $K_{\mathrm{SV} 1}$ of $1-\mathrm{AP} 200 / 19$ is $9.74 \mathrm{kPa}^{-1}$, demonstrating the high sensitivity of the film in these conditions.

To demonstrate that these new sensing films can also be used for ultra-low oxygen detection, we used synthetic air (mixture of oxygen and nitrogen) to achieve a minimum oxygen concentration of $0.05 \mathrm{kPa} \mathrm{O}_{2}$. The phase-based luminescence lifetime variations for different oxygen levels between 0 and $2.1 \mathrm{kPa} \mathrm{pO}_{2}$ are shown in ESI $\dagger$ (see Fig. S9, ESI $\dagger$ ). $\Delta \tau_{0.05}$ was used to characterize the sensitivity of the sensing films for concentrations over $0.05 \mathrm{kPa} p \mathrm{O}_{2}$. This parameter was determined following the following equation: ${ }^{5}$

$$
\Delta \tau_{0.05}=\frac{\tau_{0}-\tau_{0.05}}{\tau_{0}-\tau_{100}} \times 100
$$

where $\tau_{0}$ corresponds to the luminescence lifetime in the absence of oxygen, $\tau_{0.05}$ is the luminescence lifetime in the presence of $0.05 \mathrm{kPa}(0.05 \%)$ oxygen and $\tau_{100}$ is the luminescence lifetime in the presence of $100 \mathrm{kPa}(100 \%)$ oxygen. 1-PS has $\Delta \tau_{0.05}=1.50 \pm 0.32 \%$ while 1-AP200/19 shows a much higher $\Delta \tau_{0.05}=33.55 \pm 0.37 \%$. In practice it means that the $33.55 \%$ of the signal of the emission is quenched at $0.05 \mathrm{kPa} p \mathrm{O}_{2}$.
Comparing these results with previous works using the same methodology and same set-up (Table 1), we confidently conclude that 1-AP200/19 is more sensitive at ultra-low $\mathrm{O}_{2}$ concentrations than $\operatorname{Ir}(\mathrm{III})$ complexes (i.e. $\Delta \tau_{0.05}$ for N969, N1008 and EB146 immobilized in the same solid support and performing the measurements in the same conditions are $20.98 \pm 1.02 \%, 4.44 \pm$ $0.70 \%$ and $9.43 \pm 1.41 \%$, respectively). Among the noble metalbased sensing films, only PtTFPP-AP200/19 $\left(\Delta \tau_{0.05}=62.53 \pm 3.66 \%\right)$ displays better performance, which is one of the most sensitive films at ultra-low $\mathrm{O}_{2}$ concentration reported in the literature.

To demonstrate the practicality of these sensing films, the oxygen concentration of several air samples were measured with the films and compared with the real $\mathrm{O}_{2}$ concentrations (Table S3, $\mathrm{ESI}_{\dagger} \dagger$ ). Because of their higher sensitivity, films based on AP200/19 are more accurate with intensity methods, while both AP200/19 and PS have similar accuracy with lifetime measurements.

The quenching reaction does not consume oxygen and therefore the process is reversible as demonstrated by results shown in Fig. S4-S6 (ESI $\dagger$ ). As the most relevant application for these sensing films is trace oxygen analysis, the response and recovery times have been calculated between 1 and $5 \mathrm{kPa} p \mathrm{O}_{2}$, which provide more relevant information than response times to $100 \mathrm{kPa} p \mathrm{O}_{2}$ and recovery to anoxic condition. The $t_{95}$ response times for all of the sensing films are given in Table S4 (ESI $\dagger$ ). All of them are shorter than $11 \mathrm{~s}$ when changing from 1 to $5 \mathrm{kPa} p \mathrm{O}_{2}$ and shorter than $16 \mathrm{~s}$ when changing from 5 to $1 \mathrm{kPa} p \mathrm{O}_{2}$. The registered response times are in fact the response times of the full system that is the time needed to change $\mathrm{O}_{2}$ concentration from 1 to $5 \mathrm{kPa} p \mathrm{O}_{2}$ and vice versa.

An important concern common to all optical sensors is the degradation of their quantum efficiency following prolonged sampling and continuous illumination. To evaluate the photostability of the sensing films, they were illuminated with a UV lamp $(\lambda=315 \mathrm{~nm}$ and 6 Watt power) during $6 \mathrm{~h}$. The photostability study (Fig. 5 for 1-PS and 1-AP200/19 and Fig. S10, ESI $\dagger$ for other films) was carried out at $21{ }^{\circ} \mathrm{C}$ for three oxygen concentrations $(0,2$, and $8 \mathrm{kPa}$ ). Data were collected every hour, using intensity measurements. The most stable sensing film was 2-PS, which suffered the least degradation (12\% of the signal after 6 hours).

Finally, the effect of humidity on the sensing response was assessed to further evaluate the applicability of the films. Five sensing films based on 1-PS and 1-AP200/19 were used to determine the concentration of oxygen between 0 and $20 \mathrm{kPa}$
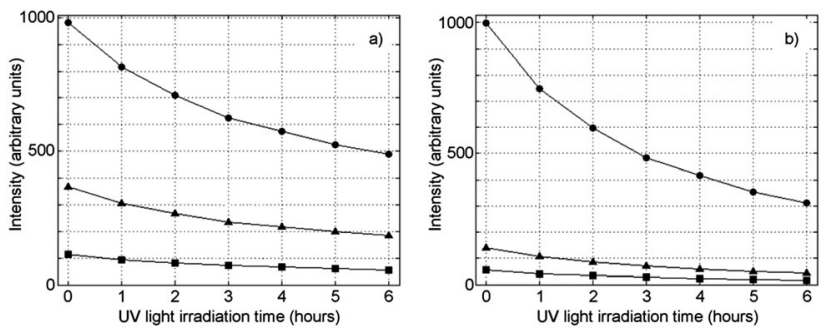

Fig. 5 Photostability of (a) 1-PS and (b) 1 -AP200/19 at $21{ }^{\circ} \mathrm{C}$ for various oxygen concentrations using intensity measurements $\left(-0 \mathrm{kPa} \mathrm{pO}_{2}\right.$; $\Delta 2 \mathrm{kPa} \mathrm{pO}_{2} ; \mathbf{\square} 8 \mathrm{kPa} \mathrm{pO}_{2}$ ). 
at different levels of relative humidity $(0,10,20,40$ and $80 \%$ $\mathrm{RH}$ ) (Fig. S11, ESI $\dagger$ ). 1-PS was not affected by RH because of the hydrophobicity of PS. On the other hand, the sensitivity of 1-AP200/19 decreased as the RH increased. It is due to the high hydrophilicity of this matrix, which had been previously pointed out. $^{7,20}$ Thus, 1-AP200/19 is more useful for gaseous analysis and the relative humidity of the environment has to be taken into account during the calibration of the sensing film.

Three luminescent $\mathrm{Cu}(\mathrm{I})$-complexes were investigated for the optical sensing of low and ultra-low oxygen concentrations using intensity and phase-based apparent lifetime measurements. The organometallic complexes were incorporated into a classical PS membrane and a nanostructured, metal oxide matrix AP200/19.

This is the first time that $\mathrm{Cu}(\mathrm{I})$ complexes have been incorporated into AP200/19. The spectral properties of these dyes are not affected by the solid support. The most sensitive sensing films are 1-AP200/19 and 2-AP200/19 $\left(K_{\mathrm{SV} 1}=5.45\right.$ and $5.13 \mathrm{kPa}^{-1}$, respectively, in the range $0-10 \mathrm{kPa} p \mathrm{O}_{2}$ ). Interestingly they show higher sensitivity than reported sensing films based on phosphorescent cyclometallated $\operatorname{Ir}(\mathrm{III})$ complexes (e.g. $K_{\mathrm{SV}}$ (N969AP200/19) $=4.79 \mathrm{kPa}^{-1}$ ) but still lower than PtTFPP complex $\left(K_{\text {SV }}(\right.$ PtTFPP-AP200/19 $\left.)=25.68 \mathrm{kPa}^{-1}\right)$. As expected from the definition of $K_{\mathrm{SV}}$, sensitivity is primarily better correlated to the lifetime of excited state of the emitting species than to the photoluminescent quantum yield of the film, which provides a direction of research to further increase the sensitivity of these promisingly low cost copper-based emitters.

Furthermore these sensing films are suitable for ultra-low oxygen detection down to $0.05 \mathrm{kPa} p \mathrm{O}_{2}$. In particular the parameter $\Delta \tau_{0.05}(33.55 \pm 0.37 \%)$ shows that $1-\mathrm{AP} 200 / 19$ is again more sensitive at ultra-low $\mathrm{O}_{2}$ concentrations than films based on Ir(III) complexes and as much as the half of the most sensitive AP200/19-based sensing films at ultra-low $\mathrm{O}_{2}$ concentration reported in the literature $\left(\Delta \tau_{0.05}\right.$ for PtTFPP-AP200/19 is $62.53 \pm 3.66 \%)$.

The reasons for the excellent performance of $\mathbf{1}$ are primarily attributed to the pertinent choice of matrix and measurement method. As other complexes are not as performing as 1, specific properties of $\mathbf{1}$ are also important for high performance. However definitive conclusions about this aspect cannot be drawn because only 1 could be fully studied.

Overall, we have clearly demonstrated that copper-based luminescent complexes are a credible alternative to more expensive emitters for oxygen sensing and deserve particular attention for the development of low cost $\mathrm{O}_{2}$ sensing films.

The authors gratefully acknowledge the financial support of the Spanish Ministry of Economy and Competitiveness (CTQ201125316 and Medina-Rodríguez's grant reference BES-2009-026919), the Regional Government of Andalusia (Excellence projects P07-FQM-2625 and P07-FQM-2738), and the European Union (MulTHIC, IEF-326107, and HetIridium, CIG-322280). Also, the authors are grateful to Ilford Imaging Switzerland $\mathrm{GmbH}$ (Switzerland) for supplying the metal oxide membranes.

\section{Notes and references}

$\$ 3$-AP200/19 gave irreproducible $\mathrm{O}_{2}$-sensing results and is not discussed further. This is attributed to its more hydrophobic nature compared to other dyes, resulting in significant aggregation in the highly polar AP200/19.

$\S$ Only films using 1 were characterized using lifetime measurements in the frequency domain (phase-resolved method) because of the impossibility to excite other films with the $375 \mathrm{~nm}$ UV LED used in our set-up.

1 N. Armaroli, G. Accorsi, F. Cardinali and A. Listorti, Top. Curr. Chem., 2007, 280, 69.

2 (a) N. Alonso-Vante, J.-F. Nierengarten and J.-P. Sauvage, J. Chem. Soc., Dalton Trans., 1994, 1649; (b) T. Bessho, E. C. Constable, M. Graetzel, A. H. Redondo, C. E. Housecroft, W. Kylberg, M. d. K. Nazeeruddin, M. Neuburger and S. Schaffner, Chem. Commun., 2008, 3717; (c) Y.-J. Yuan, Z.-T. Yu, J.-Y. Zhang and Z.-G. Zou, Dalton Trans., 2012, 41, 9594; (d) T. E. Hewat, L. J. Yellowlees and N. Robertson, Dalton Trans., 2014, 43, 4127; (e) M. S. Lazorski and F. N. Castellano, Polyhedron, 2014, 82, 57.

3 (a) J. C. Deaton, S. C. Switalski, D. Y. Kondakov, R. H. Young, T. D. Pawlik, D. J. Giesen, S. B. Harkins, A. J. M. Miller, S. F. Mickenberg and J. C. Peters, J. Am. Chem. Soc., 2010, 132, 9499; (b) M. Hashimoto, S. Igawa, M. Yashima, I. Kawata, M. Hoshino and M. Osawa, J. Am. Chem. Soc., 2011, 133, 10348; (c) F. Wei, T. Zhang, X. Liu, X. Li, N. Jiang, Z. Liu, Z. Bian, Y. Zhao, Z. Lu and C. Huang, Org. Electron., 2014, 15, 3292; (d) A. Wada, Q. Zhang, T. Yasuda, I. Takasu, S. Enomoto and C. Adachi, Chem. Commun., 2012, 48, 5340.

4 (a) N. Armaroli, G. Accorsi, M. Holler, O. Moudam, J. F. Nierengarten, Z. Zhou, R. T. Wegh and R. Welter, Adv. Mater., 2006, 18, 1313; (b) Q. S. Zhang, Q. G. Zhou, Y. X. Cheng, L. X. Wang, D. G. Ma, X. B. Jing and F. S. Wang, Adv. Funct. Mater., 2006, 16, 1203; (c) R. D. Costa, D. Tordera, E. Ortí, H. J. Bolink, J. Schonle, S. Graber, C. E. Housecroft, E. C. Constable and J. A. Zampese, J. Mater. Chem., 2011, 21, 16108.

5 S. Medina-Rodriguez, M. Marin-Suarez, J. F. Fernandez-Sanchez, A. de la Torre-Vega, E. Baranoff and A. Fernandez-Gutierrez, Analyst, 2013, 138, 4607.

6 S. M. Borisov, P. Lehner and I. Klimant, Anal. Chim. Acta, 2011, 690, 108.

7 J. F. Fernández-Sánchez, R. Cannas, S. Spichiger, R. Steiger and U. E. Spichiger-Keller, Anal. Chim. Acta, 2006, 566, 271.

8 M. T. Miller and T. B. Karpishin, Sens. Actuators, B, 1999, 61, 222.

9 L. Shi, B. Li, S. Yue and D. Fan, Sens. Actuators, B, 2009, 137, 386.

10 C. S. Smith and K. R. Mann, Chem. Mater., 2009, 21, 5042.

11 Y. Wang, B. Li, Y. Liu, L. Zhang, Q. Zuo, L. Shi and Z. Su, Chem. Commun., 2009, 5868.

12 C. S. Smith, C. W. Branham, B. J. Marquardt and K. R. Mann, J. Am. Chem. Soc., 2010, 132, 14079.

13 J. Yuasa, M. Dan and T. Kawai, Dalton Trans., 2013, 42, 16096.

14 C. S. Smith and K. R. Mann, J. Am. Chem. Soc., 2012, 134, 8786.

15 A. Kaeser, M. Mohankumar, J. Mohanraj, F. Monti, M. Holler, J.-J. Cid, O. Moudam, I. Nierengarten, L. Karmazin-Brelot, C. Duhayon, B. Delavaux-Nicot, N. Armaroli and J.-F. Nierengarten, Inorg. Chem., 2013, 52, 12140.

16 (a) C. S. Smith, C. W. Branham, B. J. Marquardt and K. R. Mann, J. Am. Chem. Soc., 2010, 132, 14079; (b) J. Yuasa, M. Dan and T. Kawai, Dalton Trans., 2013, 42, 16096; (c) R. Czerwieniec, K. Kowalski and H. Yersin, Dalton Trans., 2013, 42, 9826; (d) X.-L. Chen, R. Yu, Q.-K. Zhang, L.-J. Zhou, X.-Y. Wu, Q. Zhang and C.-Z. Lu, Chem. Mater., 2013, 25, 3910.

17 M. Marín-Suárez del Toro, J. F. Fernández-Sánchez, E. Baranoff, M. K. Nazeeruddin, M. Gräetzel and A. Fernández-Gutiérrez, Talanta, 2010, 82, 620 .

18 M. Marín-Suárez, B. F. E. Curchod, I. Tavernelli, U. Rothlisberger, R. Scopelliti, I. Jung, D. Di Censo, M. Grätzel, J. F. Fernández-Sánchez, A. Fernández-Gutiérrez, M. K. Nazeeruddin and E. Baranoff, Chem. Mater., 2012, 24, 2330.

19 S. Medina-Rodríguez, A. de la Torre-Vega, F. J. Sainz-Gonzalo, M. MarínSuárez, C. Elosúa, F. J. Arregui, I. R. Matias, J. F. Fernández-Sánchez and A. Fernández-Gutiérrez, Anal. Chem., 2014, 86, 5245.

20 J. F. Fernández-Sánchez, I. Fernández, R. Steiger, R. Beer, R. Cannas and U. E. Spichiger-Keller, Adv. Funct. Mater., 2007, 17, 1188. 